\title{
El coronavirus como enfermedad profesional (no listada). Interrogantes motivados por la calificación
}

\author{
Coronavirus as an occupational disease (not listed). \\ A series of questions motivated by the rating
}

María Paula Carril ${ }^{1}$

\begin{abstract}
Resumen
Los alcances y el impacto que tiene el covid-19 en las relaciones laborales es incuestionable. Afecta de manera transversal los derechos y obligaciones del empleador y del trabajador, en particular sobre el deber de prestación de éste y de ocupación de aquél, y obliga a todos los operadores jurídicos a indagar sobre los alcances que relacionan esta pandemia y el sistema de la LRT.

La calificación como enfermedad profesional (no listada) del covid-19 significó una respuesta que fue demandada desde el inicio de la pandemia y un remedio a la confusión que generaba la cobertura de ese espectro de trabajadores frente al escenario en que nos posicionó el contagio de la enfermedad. Pero si bien logró tales objetivos, abrió una serie de interrogantes que no resulta cuestión menor analizar y a los que, en algún momento, el derecho, concebido como sistema de normas y principios deberá dar respuesta. El coronavirus importa un riesgo del trabajo que, cumplidos ciertos presupuestos, cae en la órbita de la LRT y dispara la responsabilidad de los empleadores y de las ART. La pandemia gestó un debate - que recién comienza - en el núcleo central del sistema previsto por la Ley de Riesgos del Trabajo.
\end{abstract}

Palabras clave: coronavirus - enfermedad profesional no listada - riesgo del trabajo - decreto 367/20

\begin{abstract}
The scope and impact of the covid-19 in labor relations is unquestionable. It transversally affects the rights and obligations of both the employer and the worker, in particular regarding the duty to provide services of the latter and to employ of the former; and it forces all legal operators to inquire about the scope of the relationship between this pandemic and the Labour Risks Law system.

The classification as an occupational disease (not listed) of the covid-19 meant a response that was demanded from the beginning of the pandemic and a remedy to the confusion generated by the coverage of that spectrum of workers in the face of the scenario in which the contagion of the disease positioned us. But although it achieved these objectives, it opened a series of questions that are not minor to analyze and to which at some point, law, conceived as a system of norms and principles, will have to respond. The coronavirus imports a work risk that, once certain assumptions are met, falls into the orbit of Labour Risks Law and triggers the responsibility of employers and the occupational risk insurance companies (ART). The pandemic generated a debate - which has only just begun - in the central core of the system provided by the Labour Risks Law.
\end{abstract}

Key words: coronavirus - not listed occupational disease - occupational risk - decree 367/20

\section{Derecho / Jurisprudencia y doctrina}

Citar: Carril, M. P. (2020). El coronavirus como enfermedad profesional (no listada). Una serie de interrogantes motivada por la calificación. Omnia. Derecho y sociedad, 3 (3), pp. 111-120.

1 Fiscalía General del Superior Tribunal de Justicia de Jujuy. Abogada por la Universidad Católica de Santiago del Estero - Departamento Académico San Salvador (UCSE- DASS), Posgrado en Derecho Laboral por la Universidad de Buenos Aires (UBA), Posgrado en Diversidad Cultural y Derecho Penal por la Universidad Nacional de Jujuy (UNJU). Prosecretaria Técnica de Juzgado en Secretaría de Superintendencia del Poder Judicial de Jujuy (2013-2015) y Actuaria Fiscalía General del Superior Tribunal de Justicia de Jujuy (2015 hasta la actualidad).mpcarril@justiciajujuy.gov.ar 


\section{INTRODUCCIÓN}

Ante la inicial incertidumbre que suscitaba la existencia del coronavirus, su vinculación al mundo laboral y específicamente su condición de posible riesgo del trabajo, y la inevitable discusión doctrinaria y jurisprudencial que se abría al respecto, surgió el DNU 367/2020 como instrumento que, de alguna manera, llegó a adecuar de un modo circunstancial pero necesario el Sistema de Riesgos del Trabajo.

El recrudecimiento de la pandemia había instado de manera proporcional se emitieran pronunciamientos respecto a la preocupación que giraba en relación con los trabajadores que prestan servicios esenciales y actividades permitidas por el DNU 297/20 y resoluciones de Jefatura de Gabinete de Ministros.

El marco normativo del decreto establece que la enfermedad CoviD-19 producida por el coronavirus se considerará presuntivamente una enfermedad de carácter profesional, no listada, en los términos del ap. 2, inc. b, art. 6, Ley 24557 , respecto de las y los trabajadores dependientes excluidos mediante dispensa legal del cumplimiento del aislamiento social, preventivo y obligatorio con el fin de realizar actividades consideradas esenciales.

Para el caso del personal de la salud dispone que se considerará que la enfermedad producida por el coronavirus guarda relación de causalidad directa e inmediata con la labor efectuada, salvo prueba en contrario. La requerida protección de las condiciones de vida y de trabajo de los sectores más expuestos al riesgo que trae consigo la pandemia, era un aspecto necesario que -en el contexto de emergencia sanitaria- urgía contemplar.

La calificación como enfermedad profesional del covid-19 significó una respuesta que venía siendo demandada desde el inicio de la pandemia, y una suerte de remedio a la con- fusión que generaba la cobertura de ese espectro de trabajadores frente al escenario en que nos posicionó el contagio de la enfermedad. Pero si bien logró tales objetivos, abrió una serie de interrogantes que no resulta cuestión menor analizar y a los que en algún momento el derecho - concebido como sistema de normas y principios - deberá dar respuesta.

El coronavirus impacta de manera transversal en los derechos y obligaciones tanto del empleador como del trabajador, en particular sobre el deber de prestación de éste y de ocupación de aquél obligando a todos los operadores jurídicos a indagar sobre los alcances que relacionan esta pandemia con el sistema de la LRT.

\section{¿POR QUÉ LA CALIFICACIÓN?}

\section{Una necesaria acotación sobre los ante- cedentes del sistema}

La Ley de Riesgos del Trabajo, allá por 1995, se había enrolado en el marco de una postura esencialmente restrictiva (art. 6, ap. 2), ya que circunscribía el amparo legal a un listado cerrado de enfermedades profesionales que elaboraba y revisaba anualmente el Poder Ejecutivo, previa consulta con el Comité Consultivo Permanente. El listado era taxativo y al respecto no surgía duda alguna. El último párrafo del citado artículo era contundente: "Las enfermedades no incluidas en el listado como sus consecuencias en ningún caso serán consideradas resarcibles". En aras de cumplimentar los objetivos queridos por la norma, confeccionar un listado de enfermedades laborales amplio y comprensivo de todas las patologías vinculadas con el trabajo habría constituido la lógica amalgama con el texto; sin embargo, en la realidad sucedió todo lo contrario.

Este aspecto, sostiene Ramírez (2020) era uno de los más cuestionables de la LRT, si se 
lo confrontaba con las garantías y principios constitucionales. $Y$ es que se advierte una clara contraposición con instrumentos que conforman normas superiores de nuestro sistema legal. La Organización Internacional del Trabajo ha sostenido que el sistema de listado cerrado, que no admite que el trabajador pueda demostrar que padece una patología vinculada con su trabajo no incluida en la lista, es contrario al Convenio 42 -ratificado por Argentina- y a la Recomendación 121/1964 de la Comisión de Expertos en Aplicación de Convenios y Recomendaciones.

Una concepción acorde al sistema que inicialmente pensó el legislador, permitía considerar a una enfermedad como profesional cuando era contraída por el trabajador como consecuencia (directa e inmediata) del ejercicio de su ocupación u actividad, y respondía a un riesgo específico de esta.

A ese rigor inicial, siguió una etapa de evolución jurisprudencial que —en materia laboral- amplió el concepto y abrazó con la tutela legal a toda enfermedad en la que el trabajo constituya causa eficiente para su manifestación, desarrollo o agravación.

El sistema de la LRT importa un lógico desdoblamiento de dos situaciones: por un lado, la existencia de patologías que se presume fueron causadas por determinadas actividades que conllevan el riesgo de que el trabajador contraiga una enfermedad, para lo cual el sistema considera suficiente que el trabajador demuestre que padece la patología y que se desempeña en un ámbito laboral con capacidad para provocarla para que se presuma que se trata de una enfermedad profesional; $y$, por el otro lado, otras enfermedades laborales cuya vinculación con el trabajo deberá demostrar el dependiente.

Enseña Ramírez (2020) que"
En el sistema de la LRT hay un listado de enfermedades profesionales y un procedimiento para determinarlas, que contiene una definición de cada una, un detalle no taxativo de las actividades laborales que pueden originarlas y la forma de diagnosticarlas. Es decir que el listado de enfermedades es "cerrado", pero el detalle de tareas, productos o ámbitos laborales que pueden causarlas es ejemplificativo".

El sistema de listado cerrado de enfermedades profesionales fue inevitablemente objeto de duros embates judiciales y cuestionamientos desde los sectores de la Doctrina. Si bien el sistema tambaleó, abrió la puerta a nuevos horizontes y así apareció el Decreto 1278/2000, que trajo consigo modificaciones necesarias y que si bien pretendió limitar la apertura del listado a las enfermedades que se consideren "como provocadas por causa directa e inmediata de la ejecución del trabajo, excluyendo la influencia de los factores atribuibles al trabajador o ajenos al trabajo", la jurisprudencia fue flexibilizando la norma y ampliando la tutela como ya se dijo ut supra a enfermedades en las que el trabajo aparecía no ya como causa directa e inmediata de haberla contraído, sino como causa eficiente de aparición, desarrollo o agravamiento.

\section{La incertidumbre previa al dictado del DNU 367/20}

Casi al inicio del brote de Covid-19 en nuestro país, Ackerman (2020), desbrozando conceptos, se preguntaba si el coronavirus podría ser calificado como accidente de trabajo o enfermedad profesional. Sostenía:

... la respuesta, en ambos casos, debe ser negativa. No es accidente, en primer lugar, porque no parece posible relacionarlo causalmente con un acontecimiento súbito

Omnia. Derecho y sociedad, núm. 3, 2020: 111-120

e-ISSN 2618-4699 
y violento. A menos, claro está, que se considere que el contagio con el virus tiene esas características. Empero, y al margen de las dificultades probatorias de las circunstancias de tiempo y lugar de producción del hecho, lo cierto es que lo mismo cabría decir de cualquier otra enfermedad, que tendrá, en algún momento, su evento causal. Y, por supuesto, al no estar incluido el covID-19 en el listado aprobado por el Decreto $658 / 1996$, no puede ser considerado inicialmente como enfermedad profesional.

El jurista agregaba que podría sí intentarse la cobertura individual y excepcional; y que sería imposible pretender encuadrar la situación en las hipótesis del apartado 2. b) del artículo 6 de la Ley N² 24.557 cuando el coronavirus hubiera sido contraído en el trayecto hacia o desde el lugar de trabajo, supuesto harto probable que sólo está contemplado para los accidentes de trabajo. Enfatizó que el coronavirus era una enfermedad no laboral que, en cuanto impide la prestación del servicio, debería dar derecho al trabajador a las prestaciones dinerarias por incapacidad inculpable - a cargo del empleador- y a la atención médica y farmacéutica —otorgada por el sistema de salud-, sin perjuicio de los mayores beneficios que pudiera determinar, en la emergencia, el Gobierno.

Ramírez aseguraba que el coronavirus no era una enfermedad profesional, ya que no es un riesgo específico de ninguna actividad en particular, salvo, claro está, la de los profesionales y trabajadores de la salud, que puedan tener contacto con pacientes que se hayan contagiado, o con material contaminado. Advertía que sin embargo, el mundo laboral, no era ajeno a esta enfermedad, en particular porque la aglomeración de personas constituye riesgo cierto de contagio, por el fácil y rápido contagio en sí mismo y por la cantidad de horas que el virus es capaz de sobrevivir en algunas superficies. El doctrinario dejaba abierto un interrogante: si la enfermedad puede contraerse en cualquier lugar ¿por qué relacionarla con el trabajo?

\section{EI DNU 367/20.}

En lo medular, se declara al coronavirus

... presuntivamente una enfermedad de carácter profesional —no listada - en los términos del apartado 2, inciso b) del artículo 6 de la Ley 24557, respecto de las y los trabajadores dependientes excluidos mediante dispensa legal y con el fin de realizar actividades declaradas esenciales, del cumplimiento del aislamiento social, preventivo y obligatorio ordenado por el Decreto 297/2020 y sus normas complementarias, y mientras se encuentre vigente la medida de aislamiento dispuesta por esas normativas, o sus eventuales prórrogas, salvo el supuesto previsto en el artículo $4^{\circ}$ del presente decreto.

La idea central que instaura el decreto se sintetiza en un sistema que estructuralmente encuentra basamento en tres consideraciones: 1) aceptación de denuncia con imposibilidad de rechazo in limine; 2) cobertura inmediata de prestaciones dinerarias y médicas; 3 ) condicionalidad del reconocimiento definitivo al tránsito por el procedimiento especial del art. 6 de la LRT sobre enfermedades no listadas.

El art. 3 sienta de manera tangencial las bases del procedimiento con dos innovaciones. La primera de ellas está contenida en el primer párrafo y la constituye el procedimiento especial establecido, destinado a lograr

... la imprescindible y necesaria relación de causalidad directa e inmediata de la en- 
fermedad denunciada con el trabajo efectuado en el referido contexto de dispensa del deber de aislamiento social, preventivo y obligatorio, en los términos especificados en el artículo $1^{\circ}$.

Como bien dice Arese (2020), se ratifica aquí el principio protector, no de la víctima, sino del ya amplio y desgastado sistema de "no listadas". La segunda innovación, en palabras del citado autor, se direcciona a difuminar la línea divisoria imaginaria entre enfermedad profesional (listada o no) y la ocasionalidad como fuente de cobertura del sistema: dictaminada la CM jurisdiccional, la Comisión Médica Central

... podrá invertir la carga de la prueba de la relación de causalidad a favor del trabajador cuando se constate la existencia de un número relevante de infectados por la enfermedad covid-19 en actividades realizadas en el referido contexto, y en un establecimiento determinado en el que tuvieren cercanía o posible contacto, o cuando se demuestren otros hechos reveladores de la probabilidad cierta de que el contagio haya sido en ocasión del cumplimiento de las tareas desempeñadas en el marco referido en el artículo $1^{\circ}$ del presente.

La finalidad perseguida es lógicamente la de establecer un procedimiento compatible con la celeridad que demanda el contexto de emergencia sanitaria y la vigencia temporal de las medidas de aislamiento.

La razón de la inversión de la carga probatoria parece obedecer a que demostrar el contagio puede ser un imposible pues sabido es que se trata de un virus sumamente expansivo $y$, naturalmente invisible e inasible también probatoriamente, por supuesto. Por lo tanto, comulgando con Arese (2020), pocos podrían probar el contagio y su causalidad. En otras palabras, resulta harto dificultoso $-\mathrm{y}$ hasta improbable- demostrar en qué preciso momento alguien tomó contacto con una persona o una cosa que portaba el virus. Se apela a un haz de indicios de contagio y la probabilidad de la ocasionalidad para producirlo y así obtener la obvia calificación de enfermedad profesional.

Deberá tenerse presente que resulta altamente probable que el sistema diseñado por el decreto pueda ser discutido por las aseguradoras de riesgos del trabajo, en la medida que, con motivo de la inversión de la carga probatoria, se encuentran frente a una prueba negativa.

En el caso de los trabajadores de la salud, la causalidad establecida por el marco normativo es directa e inmediata y no necesita ser demostrada, por lo que podemos hablar de una enfermedad profesional específica, salvo prueba en contrario a cargo de la ART (art. 4 del DNU 367/2020). La presunción es, acorde a éstos lineamientos señalados, de carácter iuris tantum, y como tal, admite la prueba en contrario para desvirtuarla.

El DNU responde a los lineamientos establecidos por instrumentos que fueron ratificados por la Argentina como los Convenios 155 sobre Seguridad y Salud de los Trabajadores y su protocolo de 2002 y el 187 Marco Promocional para la Seguridad y Salud en el Trabajo, 2006 de OIT que trae un concepto amplio de accidente, enfermedad profesional o suceso peligroso (art. 1) comprensivo del coronavirus. Además, del documento de la OIT "Las normas de la OIT y el CoviD-19 (coronavirus)" del 23/3/2020(publicada el 27/3/2020) se extrae:

La enfermedad del covid-19 y el trastorno de estrés postraumático contraídos por exposición en el trabajo, podrían consider- 
arse como enfermedades profesionales ${ }^{2}$. En la medida en que los trabajadores sufran de estas afecciones y estén incapacitados para trabajar como resultado de actividades relacionadas con el trabajo, deberían tener derecho a una indemnización monetaria, a asistencia médica y a los servicios conexos.

El art. 7 establece una acotación temporal, cual es la aplicación de las disposiciones "a aquellas contingencias cuya primera manifestación invalidante se haya producido a partir de la entrada en vigencia del Decreto $N^{\circ} 297$ de fecha 19 de marzo de 2020".

\section{¿Y EL CONTAGIO IN ITINERE?}

La presunción de enfermedad profesional no listada y de la existencia de los indicios "ocasionales" generadores no resuelve el contagio in itinere. Empero, puede inferirse la existencia de entorno propicio para el contagio en el transporte o ambiente transitado para arribar o retornar del trabajo. Denunciadas esas circunstancias, también debería operar la inversión de la carga probatoria, quedando abierto el reconocimiento como enfermedad profesional.

\section{ALGUNOS TÉRMINOS AMBIGUOS QUE SERÁ NECESARIO DEFINIR Y LIMITAR. Y ALGUNAS CUESTIONES QUE DEBERÁN SER REGLAMENTADAS}

A lo largo del decreto que se viene analizando, encontramos una serie de referen- cias abiertas y términos que —un tanto ambiguos - invitan a formularse interrogantes. Sucede esto cuando la norma habla de "un número relevante de infectados". La referencia es marcadamente abierta y cabe preguntarse qué alcance se le atribuirá a la expresión: ¿a cuánto deberá ascender el número de infectados para que sea considerado relevante? Tal vez un criterio correcto pueda permitir inferir que el porcentaje de infectados debe guardar determinada proporcionalidad con la dotación de trabajadores del establecimiento de que se trate.

El DNU también refiere en el segundo párrafo del art. 3 a los términos "cercanía", "posible contacto" y "hechos reveladores". Todos ellos configuran imprecisiones que a la hora de presentarse el caso particular habrá que determinar para evitar caer en la temida inseguridad jurídica que a veces suscitan este tipo de controversias en relación a la interpretación terminológica. Y sabido es que la ambigüedad dificulta la determinación de reglas precisas al momento de configurar el nexo causal.

Las cuestiones que en el epígrafe de referencia se estima que deberán ser objeto de reglamentación son las siguientes: la forma de la denuncia, los plazos y actuaciones ante la Comisión Médica Central, la "entidad debidamente autorizada" que emite el diagnóstico que sustituye el pronunciamiento de la ART, y las excepciones a las dos presunciones que establece el decreto.

\footnotetext{
2 El párrafo 1.3.9 del anexo de la Recomendación sobre la lista de enfermedades profesionales (2002, núm. 194) recomienda que la lista nacional de enfermedades profesionales (a los fines de la prevención, registro, notificación y, de ser procedente, indemnización de las mismas debería incluir, entre otras cosas, enfermedades causadas por agentes biológicos en el trabajo cuando se haya establecido, científicamente o por métodos adecuados a las condiciones y la práctica nacionales, un vínculo directo entre la exposición a dichos agentes biológicos que resulte de las actividades laborales contraídas por el trabajador. La Recomendación especifica que, al aplicar esta lista, habrá que tener en cuenta, según proceda, el grado y el tipo de exposición, así como el trabajo o la ocupación que implique un riesgo de exposición específico.
} 


\section{EL RÉGIMEN DE LA LRT ¿ES IDÓNEOY AUTOSUFICIENTE PARA DAR RESPUESTA A LA PREVENCIÓN Y COBERTURA QUE DEMANDA LA PANDEMIA?}

Contestar la pregunta importa sincerarse sobre los alcances y la permeabilidad que el sistema debiera tener para dar adecuada respuesta a lo que la pandemia nos pone de frente y que, digámoslo sin rodeos, no tiene. Pero al menos el avance es positivo y para el universo de trabajadores de la salud, la declaración presuntiva del coronavirus como enfermedad profesional, aquieta una lógica demanda que - desde el sector- requería debida atención.

Arese (2020), en postura que comparto, aporta la idea de que la declaración del coronavirus como enfermedad profesional es el primer avance, aunque se queda en la puerta del sistema porque luego se la considera fuera del listado (ingresa pero no ingresa), apartándola de una cobertura objetiva completa y pacífica desde su denuncia. Se trata de una ingeniería jurídica ingeniosa para obligar a que opere el sistema sin un rechazo in limine (el conocido rechazo "no listada"), algo que resultaría un despropósito en el actual contexto de pandemia. Empero, para no desarticular el sistema con una nueva categoría no prevista en la LRT se obliga a aceptar el ingreso de la contingencia al sistema de forma inmediata pero condicionada por el trámite del art. 6 .

\section{¿QUÉ TANTO TIENE QUE VER EL SISTEMA DE LA LRT CON LA SEGURIDAD SOCIAL?}

Cabe preguntarse si no hubiese sido menos engorroso $-\mathrm{y}$ más simple- modi- ficar el listado e incluir al coronavirus como enfermedad profesional indicándose los factores, ambiente u ocasión de contagio, según las normas de OIT. La respuesta parece ser innegablemente afirmativa. Pero no parece tan sencillo pensar en las consecuencias mediatas de considerar al coronavirus como enfermedad listada.

El covid-19 puso en jaque el sistema contenido en la LRT. Y puso en evidencia los pormenores del modelo de seguro mercantil al que responde. Dice Ackerman (2020):

... el sistema de la LRT, no obstante las declamaciones oficiales y la pretensiones de algún sector de la doctrina, poco - si acaso algo - tiene que ver con la seguridad social, y no pasa de ser un ya anacrónico modelo de responsabilidad individual del empleador - como lo es igualmente el también vetusto régimen de los Ilamados accidentes y enfermedades inculpables-, con seguro obligatorio contratado fundamentalmente con empresas privadas con fin de lucro.

Seguro en el que el asegurado es el empleador - esto es el responsable- y no el trabajador que es quien sufre las consecuencias de las contingencias y a quien, naturalmente, debe asegurar protección la seguridad social.

Lo que es cierto es que solo estamos en presencia de un ajuste más al sistema de la LRT que dista mucho de ser un avance sustancial sobre el componente lucrativo que siempre medra entre las normas y el objetivo central del sistema de proteger la vida y la salud. A priori de otras consideraciones que pueden resultar objetivamente poco benévolas, el 
avance es algo complejo y rebuscado ${ }^{3}$, pero acerca soluciones sobre todo para la necesaria cobertura frente al riesgo del coronavirus profesional de los sectores que trabajan por la salud de toda la población.

Parafraseando a Ackerman, más que reproche al sistema de la LRT, cabría un reproche en todo caso a la histórica omisión de construir un verdadero sistema de Seguridad Social que, gestionado monopólicamente por el Estado, y apoyado en el auténtico y sincero principio de solidaridad, cumpla verdaderamente con el mandato del tercer párrafo del artículo 14 bis de la Constitución Nacional.

\section{A MODO DE CONCLUSIÓN}

Los alcances y el impacto que tiene el covID-19 en las relaciones laborales es incuestionable. Lo es también en relación a la vida misma, desde casi cualquier óptica desde que la miremos. En lo que concierne al ámbito laboral, la probabilidad de contagio en el lugar de trabajo es altísima (respecto de aquellas actividades excluidas —esenciales o permitidas- del A.S.P.O). Desde y hacia el lugar trabajo también.

EI DNU 367/2020 aparece en el mundo jurídico como instrumento que de alguna manera llegó a adecuar de un modo circunstancial pero necesario el Sistema de Riesgos del Trabajo, declarando al coronavirus

... presuntivamente una enfermedad de carácter profesional —no listada- en los términos del apartado 2, inciso b) del artículo 6 de la Ley 24557, respecto de las y los trabajadores dependientes excluidos mediante dispensa legal y con el fin de realizar actividades declaradas esenciales, del cumplimiento del aislamiento social, preventivo y obligatorio ordenado por el Decreto $297 / 2020$ y sus normas complementarias, y mientras se encuentre vigente la medida de aislamiento dispuesta por esas normativas, o sus eventuales prórrogas, salvo el supuesto previsto en el artículo $4^{\circ}$ del presente decreto.

El coronavirus importa un riesgo del trabajo que, cumplidos ciertos presupuestos, cae en la órbita de la LRT y dispara la responsabilidad de los empleadores y de las ART.

Por las presunciones que, en materia de enfermedades profesionales, juegan un rol fundamental para tener probado per se el nexo causal para determinadas profesiones o actividades, se presume de origen laboral al contagio del coronavirus. En otros casos, el damnificado deberá probar el nexo causal entre la patología eventualmente contraída y el trabajo. No obstante, también podrá operar a su favor la inversión de la carga probatoria.

La solución mediata importa una respuesta que demandaba — con justicia — brindar soluciones posibles a la cobertura frente al riesgo del coronavirus profesional de los sectores, sobre todo que trabajan por la salud, que merecen prioritaria atención por desarrollar tareas esenciales e imprescindibles, y que como héroes que son frente a esta pandemia, lo merecen más que nunca.

El DNU 367/20 y las demás medidas tomadas en el marco de la emergencia sanitaria y el aislamiento preventivo obligatorio, responden

\footnotetext{
3 En el sentido que la ya señalada ingeniería jurídica permite que resulte operativo obligar al sistema a brindar respuesta sin posibilidad de articularse un rechazo in limine, logrando del mismo modo que el mismo sistema no sufra una suerte de desarticulación con una nueva categoría no prevista en la LRT. De esta manera, se produce la obligada aceptación del ingreso de la contingencia al sistema de forma inmediata, pero condicionada por el trámite del art. 6.
} 
a una línea de implementación de políticas laborales y de seguridad social tendientes a tutelar la salud de trabajadores y trabajadoras con riesgo de exposición al coronavirus por el hecho o en ocasión de su trabajo, en consonancia con las disposiciones de la OIT al respecto.

Ojalá la pandemia nos deje un amplio abanico de enseñanzas como sociedad que permita valorar y priorizar el derecho a la vida y a la salud por sobre todas las cosas, como siempre debió ser. Y del mismo modo, y en el marco del derecho laboral, admita la tarea fundamental que algunos sectores brindan a la población, y que, a la hora de ser retribuidos, ocupan los estamentos más bajos de las prioridades.

Es indiscutible que la pandemia gestó un debate en el núcleo central del sistema previsto por la Ley de Riesgos del Trabajo, debate que recién comienza y que aún tiene mucha tela para cortar.

\section{REFERENCIAS BIBLIOGRÁFICAS}

Ackerman, M. (2020). El coronavirus abre un debate en el núcleo duro del sistema de la LRT. Rubinzal Culzoni Editores. Revista Rubinzal Online, RC D 1462/2020.

Arese, C. (2020). La compleja condición del coronavirus como enfermedad profesional según DNU 367/20. Rubinzal Culzoni Editores. Rubinzal Online, RC D 1598/2020.

Decreto de Necesidad y Urgencia $n^{\circ} 367 / 20$, disponible en www.boletinoficial.gob.ar

Ramírez, L. E. (2020). Los riesgos del trabajo en tiempos del coronavirus. Rubinzal Culzoni Editores. Revista Rubinzal Online RC 1434/2020. 
